\title{
Heterotopic pregnancy: a catastrophic event
}

\section{Neena Gupta*, Seema Dwivedi, Sangeeta Arya, Shefali Pande}

Department of Obstetrics \& Gynecology, G.S.V.M. Medical College, Kanpur, U.P., India

Received: 2 July 2013

Accepted: 23 July 2013

\section{*Correspondence:}

Dr. Neena Gupta,

E-mail: neena.gupta2211@gmail.com

(C) 2013 Gupta $\mathrm{N}$ et al. This is an open-access article distributed under the terms of the Creative Commons Attribution Non-Commercial License, which permits unrestricted non-commercial use, distribution, and reproduction in any medium, provided the original work is properly cited.

\begin{abstract}
Heterotopic gestation, although common with assisted reproductive techniques, is very rare in natural conception. A high index of suspicion can help in timely diagnosis and appropriate intervention. We report a case of heterotopic pregnancy in a 25-year-old woman presenting with hemoperitoneum from ruptured tubal pregnancy with live intrauterine gestation at 12 weeks of amenorrhea, diagnosed on ultrasound examination.
\end{abstract}

Keywords: Adnexal mass, Assisted conception, Heterotopic

\section{INTRODUCTION}

Heterotopic pregnancy is defined as the coexistence of intrauterine and extrauterine gestation. The incidence of heterotopic pregnancy is very low.

The frequency was originally estimated on theoretical basis to be 1 in 30,000 pregnancies.

We present a rare case of heterotopic pregnancy with live intrauterine gestation and ruptured left ectopic pregnancy in natural conception.

\section{CASE REPORT}

A 25-year-old woman, G4P2 L2A1, with 12 weeks of amenorrhea presented to our Department with chief complaints of acute pain in abdomen for 2 hours and acute onset breathlessness for $1 \mathrm{hr}$ with clinical features of shock with very low general condition.

On examination, her general condition was very poor, her blood pressure was 60 systolic, P.R. was 160/min., R.R 34/min, afebrile, pallor +++; Per Abdominal examination revealed distended tense abdomen with tenderness.

P/S- Slight blood mixed discharge was present.
Urine pregnancy test was positive.

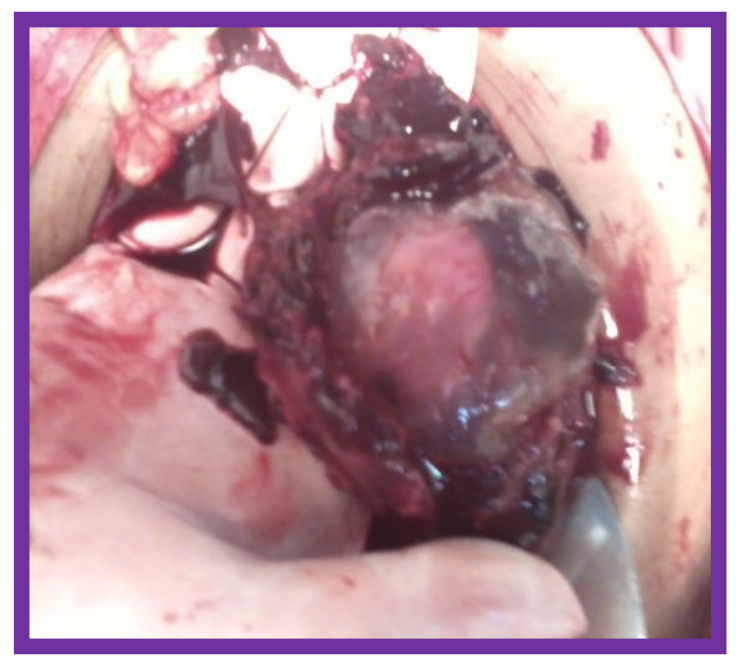

Figure 1: Ruptured left tubal ectopic with gestational sac in situ.

Transabdominal ultrasound revealed single live intrauterine fetus of approximately 12 weeks with variable presentation. A complex left adnexal cystic mass (showing fetal node of 12 weeks with cardiac activity) was present. There was moderate amount of free fluid in 
peritoneal cavity- hemoperitoneum? Gaseous distended bowel loops were present.

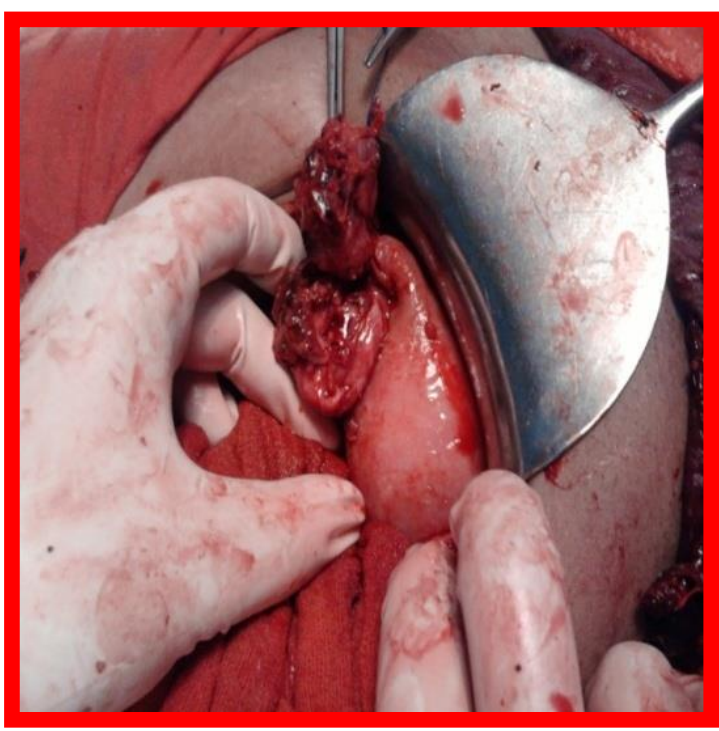

Figure 2: Ruptured left tubal ectopic with bulky uterus.

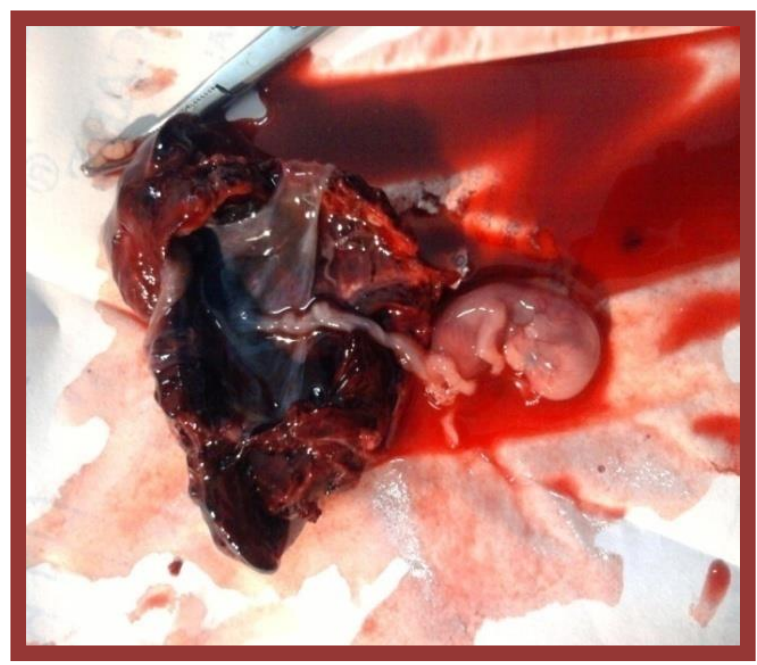

Figure 3: Fetus with gestation SAC.

Provisional diagnosis of a heterotopic pregnancy with ruptured left ectopic gestation was suggested in view of clinical history, moderate amount of free intraperitoneal fluid, and an intrauterine gestation.

The patient underwent emergency exploratory laparotomy. There was ruptured left-sided tubal pregnancy with alive fetus with hemoperitoneum and left sided salpingectomy was performed; the intrauterine live gestation was allowed to continue.

\section{DISCUSSION}

A heterotopic gestation is difficult to diagnose clinically. Typically, laparotomy is performed because of ruptured tubal pregnancy. Similar situation was encountered in our case also. Laparotomy was performed on the basis of suspicion. Heterotopic gestation was diagnosed peroperatively. At the same time, uterus is congested, softened, and enlarged as seen in this case; ultrasound examination can nearly always show gestational products in uterus.

The incidence was originally estimated on theoretical basis to be 1 in 30,000 pregnancies. However, more recent data indicate that the rate is higher due to assisted reproduction and is approximately 1 in 7000 overall and as high as 1 in 900 with ovulation induction. ${ }^{1,2}$

The increased incidence of multiple pregnancy with ovulation induction and IVF increases the risk of both ectopic and heterotopic gestation. The hydrostatic forces generated during embryo transfer may also contribute to the increased risk. ${ }^{1}$

There may be an increased risk in patients with previous tubal surgeries. ${ }^{3}$

Heterotopic pregnancy can have various presentations. It should be considered more likely (a) after assisted reproduction techniques, (b) with persistent or rising chorionic gonadotropin levels after dilatation and curettage for an induced/spontaneous abortion, (c) when the uterine fundus is larger than for menstrual dates, (d) when more than one corpus luteum is present in a natural conception, and (e) when vaginal bleeding is absent in the presence of signs and symptoms of ectopic gestation. ${ }^{4}$

There was no risk factor in our case, heterotopic pregnancy occurred after natural conception.

A heterotopic gestation can also present as hematometra and lower quadrant pain in early pregnancy. ${ }^{5}$

Most commonly, the location of ectopic gestation in a heterotopic pregnancy is the fallopian tube, which was in our case. However, cervical and ovarian heterotopic pregnancies have also been reported. ${ }^{6,7}$

Majority of the reported heterotopic pregnancies are of singleton intrauterine pregnancies. Triplet and quadruplet heterotopic pregnancies have also been reported, though extremely rare. ${ }^{8,9}$ It can be multiple as well. ${ }^{4}$ They can be seen frequently with assisted conceptions.

Intrauterine gestation with hemorrhagic corpus luteum can simulate heterotopic/ectopic gestation both clinically and on ultrasound. ${ }^{10}$

Other surgical conditions of acute abdomen can also simulate heterotopic gestation clinically and hence the difficulty in clinical diagnosis. Bicornuate uterus with gestation in both cavities may also simulate a heterotopic pregnancy. 
High resolution transvaginal ultrasound with color Doppler will be helpful as the trophoblastic tissue in the adnexa in a case of heterotopic pregnancy shows increased flow with significantly reduced resistance index. ${ }^{2}$

The treatment of a heterotopic pregnancy is laparoscopy/laparotomy for the tubal pregnancy. ${ }^{4}$

The illustrated case did not have any risk factor for the heterotopic gestation and presented with ruptured tubal pregnancy with hemodynamic instability due to hemoperitoneum. Exploratory laparotomy with left salpingectomy was performed.

Intrauterine pregnancy was allowed to continue.

The postoperative period was uneventful. Patient was discharged in a satisfactory condition and is now in regular followup.

\section{CONCLUSION}

A heterotopic pregnancy, though extremely rare, can still result from a natural conception; it requires a high index of suspicious for early and timely diagnosis; a timely intervention can result in a successful outcome of the intrauterine fetus. ${ }^{11}$

\section{REFERENCES}

1. Lyons EA, Levi CS, Sidney M. In: Dashefsky in diagnostic ultrasound. 2nd ed. Rumak CM, Wilson SR, Charboneau WK, editors. Volume 2. Mosby; 1998. p. 999.
2. Glassner MJ, Aron E, Eskin BA. Ovulation induction with clomiphene and the rise in heterotopic pregnancies: A report of two cases. J Reprod Med. 1990;35:175-8.

3. Gruber I, Lahodny J, Illmensee K, Losch A. Heterotopic pregnancy: Report of three cases. Wien Klin Wochenschr. 2002;114:229-32.

4. Ectopic Pregnancy, text book of -Williams Obstetrics. 21st ed. Multifetal Ectopic Pregnancy in Chapter 34; pp. 888-9.

5. Cheng PJ, Chueh HY, Qiu JT. Heterotopic pregnancy in a natural conception cycle presenting as haematomatra. Obstet Gynecol. 2004;104:195-8.

6. Hirose $\mathrm{M}$, Nomura $\mathrm{T}$, Wakuda $\mathrm{K}$, Ishguro $\mathrm{T}$, Yoshida Y. Combined intrauterine and ovary pregnancy: A case report. Asia Ocaena J Obstet Gynaecol. 1994;20:25.

7. Peleg D, Bar-Hava I, Neaman-Leavin M, Ashkena, Ben-Rafaelz IJ. Early diagnosis and successful non surgical treatment of viable combined intrauterine and cervical pregnancy. Fertil Steril. 1994;62:405.

8. Alsunaidi MI. An unexpected spontaneous triplet heterotopic pregnancy. Saudi Med J. 2005;26:136-8.

9. Sherer DM, Scibetta JJ, Sanko SR. Heterotopic quadruplet gestation with laparoscopic resection of ruptured interstitial pregnancy and subsequent successful outcome of triplets. Am J Obstet Gynecol. 1995; $172: 216$.

10. Sohail S. Haemorrhagic corpus luteum mimicking heterotopic pregnancy. J Coll Physicians Surg Pak. 2005;15:180-1.

11. Espinosa PM, Alcantar Mendoza MA. Heterotopic pregnancy: Report of a case and review of literature. Ginecol Obstet Mex. 1997;65:482-6.

DOI: $10.5455 / 2320-1770 . i j \operatorname{rog} 20130948$

Cite this article as: Gupta N, Dwivedi S, Arya S, Pande S. Heterotopic pregnancy: a catastrophic event. Int J Reprod Contracept Obstet Gynecol 2013;2:467-9. 